\title{
Comparison of Treatment Adherence between Selective Serotonin Reuptake Inhibitors and Moclobemide in Patients with Social Anxiety Disorder
}

\author{
Se-Won Lim ${ }^{1 *}$, Yong-Seok Kwon ${ }^{1 *}$, Juwon Ha1, Hyeng-Geun Yoon, Seung-Min Bae ${ }^{2}$, \\ Dong-Won Shin ${ }^{1}$, Young-Chul Shin ${ }^{1}$ and Kang-Seob Oh ${ }^{1 凶}$ \\ 1'Department of Psychiatry, Kangbuk Samsung Hospital, Sungkyunkwan University School of Medicine, Seoul, Korea \\ 2Department of Psychiatry, Gil Hospital, Gachon University of Medicine and Science, Incheon, Korea
}

\begin{abstract}
Objective With respect to the pharmacotherapy of social anxiety disorder (SAD), it has been suggested that treatment duration is an important factor that can significantly predict responses. The present study aimed to compare the treatment adherence of SAD patients who were taking either SSRIs or reversible inhibitors of MAO-A (moclobemide) by measuring treatment duration and all-cause discontinuation rates of pharmacotherapy in a natural clinical setting.

Methods We retrospectively analysed the data of 172 patients diagnosed with SAD. Depending on their medication, we divided the patients into two groups, SSRI $(n=54)$ or moclobemide $(n=118)$. The expected number of all-cause discontinuation every 2 weeks after starting treatment was calculated by life table survival methods. A multi-variable Cox proportional hazard regression was used to analyze the potential influence of explanatory variables.

Results Treatment duration was significantly longer in the SSRI group [46.41 \pm 56.96 , median=12.0 (weeks)] than in the moclobemide group [25.53 \pm 34.74 , median $=12.0$ (weeks), $\mathrm{Z}=2.352$, $\mathrm{p}=0.019]$. Overall, all-cause discontinuation rates were significantly lower with SSRIs $(81 \%)$ than moclobemide $\left(96 \%, \chi^{2}=4.532, \mathrm{p}=0.033\right)$.

Conclusion The SSRI group had a longer treatment duration and lower all-cause discontinuation rate than moclobemide. Further, only the type of medication had a significant effect on all-cause discontinuation rates and therefore, we could predict better treatment adherence with the SSRIs in the treatment of SAD.

Psychiatry Investig 2012;9:73-79
\end{abstract}

Key Words Social anxiety disorder, SSRI, Moclobemide, Treatment adherence, All-cause discontinuation.

\section{INTRODUCTION}

The clinical importance of social anxiety disorder (SAD, also known as social phobia) has increased gradually due to the high prevalence and significant impairments in patients' social, educational, and physical functioning. ${ }^{1-3}$ The onset of SAD typically occurs in the first decade of a patient's life, and because of SAD's long-lasting, disabling symptoms, with var-

Received: July 5, 2011 Revised: August 30, 2011

Accepted: September 9, 2011 Available online: January 18, 2012

*These authors contributed equally to this work.

$\triangle$ Correspondence: Kang-Seob Oh, MD, PhD

Department of Psychiatry, Kangbuk Samsung Hospital, Sungkyunkwan University School of Medicine, 108 Pyeong-dong, Jongno-gu, Seoul 110-746 Korea Tel: +82-2-2001-2213, Fax: +82-2-2001-2211, E-mail: ks2485@empal.com

(a) This is an Open Access article distributed under the terms of the Creative Commons Attribution Non-Commercial License (http://creativecommons.org/licenses/bync/3.0) which permits unrestricted non-commercial use, distribution, and reproduction in any medium, provided the original work is properly cited. ious comorbidities, the disorder's clinical course is usually chronic and unremitting. 4,5

To date, clinicians and researchers have used various antidepressants for treating and studying SAD. Until recently, irreversible monoamine oxidase inhibitor (MAOI) phenelzine was considered the best-established and, possibly the most efficacious pharmacologic treatment option for SAD. ${ }^{6-8} \mathrm{How}-$ ever, MAOIs require patients to follow strict diet restrictions in order to avoid severe hypertensive crises after ingestion of tyramine-rich food, such as a cheese or a Kimchi, especially in Korea; thus, MAOIs' general tolerability may be a concern over both short- and long-term treatment. ${ }^{9}$ For such reasons, clinicians tend to prefer reversible inhibitors of monoamine oxidase A (RIMAs) rather than MAOIs in Korea. Among the RIMAs, moclobemide has been less likely to be associated with hypertensive crises, ${ }^{9}$ and has demonstrated superior efficacy to placebo in some, ${ }^{8,10}$ but not all double-blind stud- 
ies. ${ }^{11,12}$ In this respect, selective serotonin reuptake inhibitors (SSRIs) have provided another possibility for the pharmacotherapy of SAD. As such, the efficacy of SSRIs was superior to placebo ${ }^{13-15}$ and similar to the efficacy of moclobemide. ${ }^{16}$

In the treatment of other anxiety disorders, there is evidence that certain factors, such as earlier age of onset or having a comorbid disorder, might play roles as negative predictors of response to pharmacotherapy; ${ }^{17,18}$ however, there is little available data about predictors of response in SAD. The treatment duration has been reported to be one of the most important clinical factors for successful treatment in the pharmacotherapy of SAD. ${ }^{19}$ Previous studies ${ }^{4,8,20,21}$ using MAOI in a long term follow-up also suggested that sufficient treatment duration is important in relapse prevention. However, there has been little available data directly comparing treatment duration between MAOIs and other drugs in SAD in terms of treatment adherence.

An analysis of a large group of SAD patients treated with the paroxetine demonstrated that only treatment duration significantly predicted treatment response. ${ }^{1}$ Therefore, adherence to pharmacotherapy is critical in order to obtain successful clinical outcomes in SAD. For these reasons, it might be very important to choose the right medication, one which has good efficacy and tolerability over a long period of treatment.

There has been evidence that, despite MAOIs' good efficacy, clinicians no longer consider non-selective MAOIs as first-line or maintenance therapy due to several limitations in their use. Therefore, moclobemide and SSRIs which have fewer limitations ${ }^{16,22}$ than non-selective MAOIs have been recently prescribed as the first-line medication in SAD. Although both moclobemide and SSRIs demonstrated superior efficacy to placebo in $\mathrm{SAD}_{,}^{23}$ there has been little available data comparing their treatment duration, which is important factor for successful pharmacotherapy in SAD. ${ }^{1}$ Based on these findings, we compared treatment durations and all-discontinuation rates retrospectively in SAD patients who were taking either SSRIs or moclobemide in a natural clinical setting.

\section{METHODS}

\section{Participants}

The current study was approved by the ethics committee of Kangbuk Samsung Hospital. The participants' information was gathered retrospectively from medical records from the Social Phobia Clinic at Kangbuk Samsung Hospital. The diagnosis of SAD was made by a well-experienced psychiatrist (the corresponding author, Dr. Oh KS) through a clinical interview according to the Diagnostic and Statistical Manual of Mental Disorders 4th edition (DSM-IV) ${ }^{24}$ and confirmed by the
Mini International Neuropsychiatric Interview (MINI). ${ }^{25}$ Clinical data for patients whose pharmacotherapy for SAD had started between January, 2005 and December, 2007 in an outpatient clinical setting were evaluated in the current study. If his or her primary diagnosis was SAD, we included patients with comorbidity for other psychiatric disorders, such as other anxiety disorders and/or mood disorders which were also diagnosed in the same manner as mentioned above. A total of 264 patients' data were collected, and we excluded any patient with a past history or current diagnosis of other psychotic disorders ( $\mathrm{n}=2)$, a significant medical illness $(\mathrm{n}=3)$, a neurological condition $(\mathrm{n}=1)$, or other Axis I primary psychiatric disorders $(\mathrm{n}=26)$. As a result, $232 \mathrm{SAD}$ patients remained, and among them, data for 172 patients who were treated with SSRIs or moclobemide were analysed in this study.

\section{Pharmacotherapy and measures}

Well-experienced psychiatrists treated all patients with either SSRIs or moclobemide in flexible doses, based on his clinical judgment. The SSRIs used in this study included paroxetine, sertraline, and escitalopram. Escitalopram is approved for the pharmacotherapy of SAD in Korea by the Korea Food and Drug Administration (KFDA) unlike in the U.S.A. Because this study was an observational study in a natural clinical setting, there was no limitation regarding the use the benzodiazepines and/or the beta-blockers based on the psychiatrist's judgement.

We measured treatment duration as the time to discontinuation of medications in weeks. Further, we defined all-cause discontinuation as patients who had stopped or switched their current medication for whatever reason, which was made by his or her prescribed psychiatrist, although we did not define "termination of treatment" in this study.

All-cause discontinuation is a composite measure of 4 components, which consisted of lack of pharmacological efficacy, drug tolerability, clinician decision, and patient decision. ${ }^{26}$ Based on Stoup and colleagues, ${ }^{26}$ the original concept of the allcause discontinuation was used to compare the effectiveness of antipsychotic drugs in schizophrenia patients, given that these patients stop or change medication frequently, and that it is hard to measure many individual factors which caused discontinuation of treatment. ${ }^{27}$ Despite some of the limitations, ${ }^{27}$ the concept of all-cause discontinuation is a meaningful clinical measurement which reflected both efficacy and side effects for both the clinician and patients. We compared not only the overall all-cause discontinuation rates between the SSRI and the moclobemide groups, but also compared the proportion of all-cause discontinuation at 4, 12, 24, 48 , and 96 weeks after starting medication. 


\section{Data analysis}

First, we compared the data descriptively between the SSRI and moclobemide groups. We used a Pearson's chi-square test to compare categorical demographic profiles and a Mann Whitney U-test to examine differences in continuous variable characteristics, such as age, onset age, and treatment duration. Results have been expressed as means \pm SD for quantitative variables or as percentages for qualitative variables.

In order to compare the observed number of all-cause discontinuation with what would be expected between the SSRI

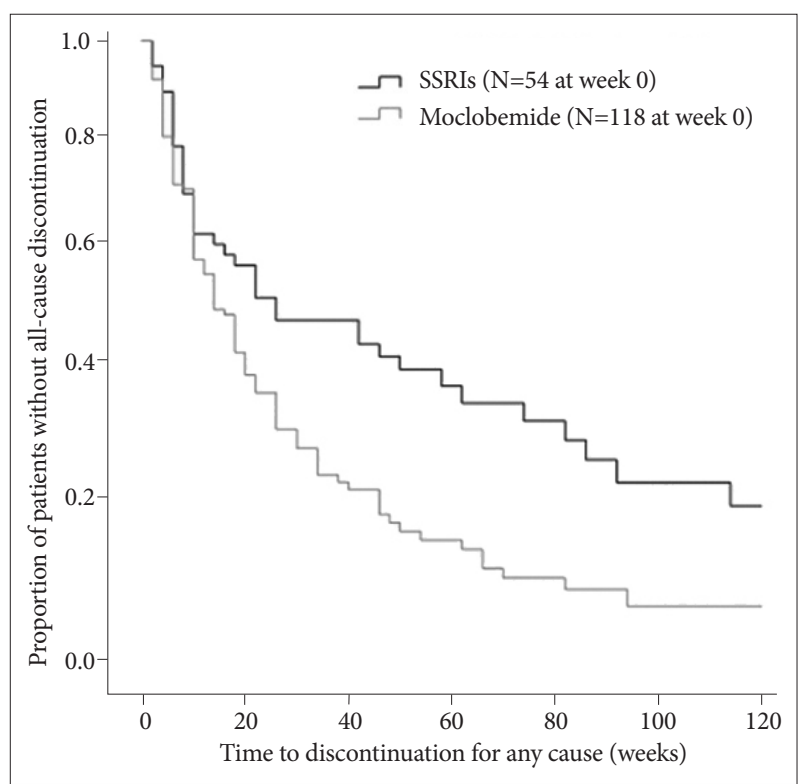

Figure 1. Proportion of patients without all-cause discontinuation over the treatment course in the SSRI and Moclobemide groups SSRI: Selective Serotonin Reuptake Inhibitor. and moclobemide groups, the expected number of all-cause discontinuation every 2 weeks after starting medication was calculated under the assumption that each patient's risk of discontinuation would be equal to the risk of the general population. To analyse this risk, life table survival methods were used. ${ }^{28}$ Life table survival curves were generated to quantify the time to each medication discontinuation or switching, and to compare the survival curves between two medication groups during the total treatment period after starting medications. Differences in survival curves for both groups were compared using the Wilcoxon statistic (Figure 1).

Lastly, the potential influence of various explanatory variables on all-cause discontinuation after starting medication was investigated using a multi-variable Cox proportional hazard regression test. ${ }^{29}$ We did a regression analysis with allcause discontinuation as the dependent variables and items including type of drug (SSRIs versus with moclobemide), gender, education level, employment status, marital status, onset age, and comorbidiy (depression, anxiety, and others) as the independent variables (Table 3). SPSS version 12.0 for Microsoft Windows was used for these analyses, and the level of statistical significance was set at $\mathrm{p}=0.05$.

\section{RESULTS}

Of 172 patients, 54 (31.40\%) were treated with SSRIs, which included paroxetine $(n=41,75.93 \%)$, escitalopram $(n=12$, $22.22 \%)$, and sertraline $(n=1,1.86 \%)$. The remaining 118 patients received moclobemide only $(68.60 \%)$.

Most patients in the current study were in the 17-69 age range, and the mean age of all patients was $35.02 \pm 12.08$ years.

Table 1. Demographic and clinical characteristics of subjects in the SSRI and Moclobemide groups

\begin{tabular}{|c|c|c|c|c|}
\hline & SSRI $(\mathrm{N}=54)$ & Moclobemide $(\mathrm{N}=118)$ & Statistical & م \\
\hline & $\mathrm{N}(\%)$ or mean $\pm \mathrm{SD}$ & $\mathrm{N}(\%)$ or mean $\pm \mathrm{SD}$ & value & $\mathrm{p}$-value \\
\hline Gender (male) & $34(62.96)$ & $79(69.30)$ & $0.261^{\dagger}$ & 0.609 \\
\hline Age (years) & $32.87 \pm 12.37$ & $36.01 \pm 11.86$ & $1.740^{\ddagger}$ & 0.082 \\
\hline Education ( $\geq 13$ years) & $23(42.59)$ & 73 (61.86) & $5.579^{\dagger}$ & $0.018^{*}$ \\
\hline Employment (no) & $11(20.37)$ & $10(8.47)$ & $4.602^{\dagger}$ & $0.032^{*}$ \\
\hline Marital status (married) & $31(57.41)$ & $49(41.53)$ & $3.669^{\dagger}$ & 0.055 \\
\hline Age of onset (years) & $23.83 \pm 11.50$ & $20.61 \pm 9.36$ & $-1.972^{\ddagger}$ & 0.085 \\
\hline Subtype (generalized) & $23(42.59)$ & $51(43.22)$ & $0.006^{\dagger}$ & 0.938 \\
\hline \multicolumn{5}{|l|}{ Comorbidity } \\
\hline All comorbidities & $34(62.96)$ & $43(36.44)$ & $10.539^{\dagger}$ & $0.001^{*}$ \\
\hline Depression & $15(44.12)$ & $26(60.47)$ & & \\
\hline Anxiety & $16(47.06)$ & $9(20.93)$ & & \\
\hline Others & $3(8.82)$ & $8(18.60)$ & & \\
\hline Duration of treatment (weeks) & $46.41 \pm 56.96$ & $25.53 \pm 34.74$ & $-2.352^{\ddagger}$ & $0.019^{*}$ \\
\hline
\end{tabular}

${ }^{*} \mathrm{p}<0.05,{ }^{\dagger}$ chi-square test $\left(\chi^{2}\right),{ }^{\ddagger}$ mann-whitney U test $(Z)$. SSRI: Selective Serotonin Reuptake Inhibitor, SD: standard deviation 
There were no significant differences between the SSRIs and moclobemide groups with regard to gender and mean age (Table 1). We found a significant difference in education level between SSRI-treated patients and moclobemide-treated patients $\left(\chi^{2}=5.579, \mathrm{p}=0.018\right)$, with SSRI-treated patients having a significantly lower rate of high-school graduation $(n=23$, $42.59 \%$ vs. $n=73,61.86 \%$ ). There was also a significant difference regarding employment, with the SSRI group having more employed participants than the moclobemide group ( $n=11,20.37 \%$ vs. $n=10,8.47 \%, \chi^{2}=4.602, p=0.032$; Table 1 ).

Among the clinical characteristics, the mean onset age of all patients was $21.62 \pm 10.16$ years, and there was no significant difference in mean onset age between the SSRI and moclobemide groups $(Z=-1.721, p=0.085)$. Upon classifying SAD into generalized and non-generalized subtypes 24, we found no significant difference between the two groups regarding subtype distribution $\left(\chi^{2}=0.006, \mathrm{p}=0.938\right)$; however, SSRItreated patients had more comorbidities than the moclobemide group, and this was statistically significant $(n=34,62.96 \%$ vs. $\mathrm{n}=43,36.44 \% ; \chi^{2}=10.539, \mathrm{p}=0.001$ ). The most common comorbidity of the SSRI group was other anxiety disorders (47.06\%), while in the moclobemide group, depression was most common (60.47\%). Based on the Mann Whitney U-test, we found a significant difference in treatment duration between the two groups, with the SSRI group showing a longer duration ( $46.41 \pm 56.96$ vs. $25.53 \pm 34.74$ weeks; $Z=-2.352$, $\mathrm{p}=0.019$; Table 1).

Figure 1 shows the survival curves for time to all-cause dis-

Table 2. Life-table survival analysis in the SSRI and Moclobemide groups

\begin{tabular}{|c|c|c|c|c|c|c|c|c|c|}
\hline \multirow[b]{2}{*}{$\begin{array}{l}\text { Interval } \\
\text { (weeks) }\end{array}$} & \multicolumn{3}{|c|}{ SSRI } & \multicolumn{3}{|c|}{ Moclobemide } & \multirow[b]{2}{*}{ Wilcoxon $\chi^{2}$} & \multirow[b]{2}{*}{$\mathrm{df}$} & \multirow[b]{2}{*}{$\mathrm{p}$-value } \\
\hline & $\begin{array}{l}\text { Entering } \\
\text { interval } \\
(\mathrm{N})\end{array}$ & $\begin{array}{c}\text { Withdrawing } \\
\text { during } \\
\text { interval }(\mathrm{N})\end{array}$ & $\begin{array}{c}\text { Cumulative } \\
\text { proportion } \\
\text { surviving (\%) }\end{array}$ & $\begin{array}{c}\text { Entering } \\
\text { interval } \\
(\mathrm{N})\end{array}$ & $\begin{array}{c}\text { Withdrawing } \\
\text { during } \\
\text { interval }(\mathrm{N})\end{array}$ & $\begin{array}{c}\text { Cumulative } \\
\text { proportion } \\
\text { surviving (\%) }\end{array}$ & & & \\
\hline 0 & 54 & 0 & 100 & 118 & 0 & 100 & & & \\
\hline 4 & 48 & 6 & 89 & 94 & 24 & 80 & 2.185 & 1 & 0.139 \\
\hline 12 & 33 & 11 & 61 & 63 & 55 & 54 & 4.532 & 1 & 0.073 \\
\hline 24 & 27 & 27 & 50 & 39 & 79 & 33 & 2.943 & 1 & 0.086 \\
\hline 48 & 21 & 33 & 39 & 15 & 103 & 13 & 5.543 & 1 & 0.019 \\
\hline 96 & 7 & 47 & 13 & 8 & 115 & 6 & 5.509 & 1 & 0.019 \\
\hline
\end{tabular}

SSRI: Selective Serotonin Reuptake Inhibitor

Table 3. Hazard ratio of all-cause discontinuation during an observation period for patients in the SSRI and Moclobemide groups

\begin{tabular}{|c|c|c|c|}
\hline \multirow{2}{*}{ Variables } & \multicolumn{3}{|c|}{ All-cause discontinuation } \\
\hline & p-value & HR & $95 \% \mathrm{CI}$ \\
\hline \multicolumn{4}{|l|}{ Medication } \\
\hline Moclobemide (reference: SSRIs) & 0.008 & 1.707 & $1.148-2.538$ \\
\hline \multicolumn{4}{|l|}{ Gender } \\
\hline Female (reference: male) & 0.678 & 0.928 & $0.654-1.318$ \\
\hline \multicolumn{4}{|l|}{ Education } \\
\hline$\geq 13$ years (reference: $<13$ years) & 0.974 & 1.006 & $0.708-1.429$ \\
\hline \multicolumn{4}{|l|}{ Employment } \\
\hline Yes (reference: none) & 0.382 & 1.254 & $0.755-2.084$ \\
\hline \multicolumn{4}{|l|}{ Marital status } \\
\hline Married (reference: separated, divorced or widowed) & 0.662 & 1.084 & $0.756-1.555$ \\
\hline \multicolumn{4}{|l|}{ Age of onset } \\
\hline$\geq 18$ years (reference: $<18$ years) & 0.979 & 1.005 & $0.715-1.412$ \\
\hline Comorbidity (reference for each class: no disorder) & 0.156 & & \\
\hline Depression & 0.052 & 0.052 & $0.003-1.031$ \\
\hline Anxiety & 0.597 & 1.224 & $0.579-2.586$ \\
\hline Others & 0.621 & 1.226 & $0.546-2.757$ \\
\hline
\end{tabular}

HR: hazard ratio, CI: confidence interval, SSRI: Selective Serotonin Reuptake Inhibitor

76 Psychiatry Investig 2012;9:73-79 
continuation between the SSRI and moclobemide group. The current study's overall number of all-cause discontinuation was 148 (86.05\%). The overall all-cause discontinuation rate was $81 \%$ and $96 \%$ for the SSRI moclobemide groups, respectively. Although both groups showed relatively high all-cause discontinuation rates, the overall all-cause discontinuation rate was significantly lower for the patients in the SSRI group, compared with the patients with the moclobemide group $\left(\chi^{2}=4.532, \mathrm{p}=0.033\right)$. That is, the SSRI treatment group had better treatment adherence than the moclobemide group. Median times to all-cause discontinuation were 24.0 weeks and 13.33 weeks for the SSRI and moclobemide groups, respectively.

A comparison of cumulative surviving proportion at some point during the treatment period in the SSRI and moclobemide group has been provided in Table 2 . There was no significant difference for the cumulative surviving proportion within 12 weeks, which indicated a relative early phase of treatment between the two groups. However, the cumulative surviving proportions were significantly different between the SSRI and moclobemide group at weeks 48 (39\% vs. $13 \%$, $\left.\chi^{2}=5.543, \mathrm{p}=0.019\right)$ and $96\left(13 \%\right.$ vs. $\left.6 \%, \chi^{2}=5.509, \mathrm{p}=0.019\right)$, indicating a relatively late phase of treatment.

Table 3 presents the results of a multi-variable hazard model. Seven explanatory variables were investigated with respect to possible effects on the hazard of all-cause discontinuation in the observation period as mentioned above. The only significant variable that influenced all-cause discontinuation was the type of medication ( $\mathrm{HR}=1.707,95 \% \mathrm{CI}=1.148-2.538$, $\mathrm{p}<0.008$ ). In particular, 3 variables (education level, employment status, and comorbidity) were statistically different between the SSRI and moclobemide groups in a comparison analysis which did not significantly influence on all-cause discontinuation. Among the comorbidity, although depression, anxiety, and other psychiatry disorders had no statistically significant effect on all-cause discontinuation, patients with depression showed a tendency of premature treatment termination $(\mathrm{HR}=0.052,95 \% \mathrm{CI}=0.003-1.031, \mathrm{p}=0.052)$.

\section{DISCUSSION}

In current study, patients treated with SSRIs had statistically significant longer treatment durations than those treated with moclobemide. We also observed that the group treated with SSRIs had significantly lower rates of all-cause discontinuation than the moclobemide group suggesting adherence of the SSRIs could be better than the moclobemide in the pharmacotherapy of SAD. If we consider this study as an extension of an earlier study by Stein et al., ${ }^{1}$ we could expect better clinical outcomes possibly with the SSRIs than with moclobemide in the treatment of SAD, although we did not compare the efficacy or the response directly between two groups.

In clinical trials with antidepressants, participant discontinuation commonly occurs for several reasons. There are early and late discontinuation, according to the point at which participants discontinue at an acute phase or at a relatively late point in the treatment period and there may be differences in the reasons between two cases. For example, adverse drug effects may lead to relatively early termination during the first few weeks. ${ }^{30}$ Generally, insufficient response could cause a participant to stop a treatment near the end of the treatment process. ${ }^{31,32}$ Besides these factors, potential discontinuation risk can be viewed as the result of complex interaction among several predisposing factors, such as demographic, social, economic, and treatment related factors, such as comorbidity, past treatment history, and psychosocial interventions. With respect to these, all-cause discontinuation which was mentioned early in this article is a rather suitable outcome measurement for the comparison of treatment discontinuation in the current study. Further, if different all-cause discontinuation rates arose among the medication groups, it would be important to identify the crucial causes for discontinuation. ${ }^{26}$ As in other clinical trials, most patients treated with the antidepressants discontinue the treatment because of adverse effects ${ }^{33}$ and thus, we considered the differences in tolerability between the two groups.

Because in current study we did not directly assess adverse effects in both groups, we could only infer reasons for discontinuation or switching drugs from the cumulative surviving proportion at 4, 12, 24, 48, and 96 weeks of observation. In the current study, the fact that about $89 \%$ of patients treated with SSRIs and $80 \%$ of patients treated with moclobemide persisted with therapy for 4 weeks ( $p=0.139$ ), which represents the acute treatment phase, suggested that perhaps adverse effects do not cause patients to discontinue treatment. ${ }^{31}$ Although some participants might have had adverse effects in the relatively late period of treatment, we did not directly assess them.

In this study, the moclobemide group exhibited lower surviving proportions at weeks 48 and 96 than the SSRI group. However, we cannot postulate that this difference is related with varying efficacy between the two groups because there was no direct measurement of efficacy or response. Therefore, we can only assume that the SSRI group had better treatment adherence than the moclobemide group.

In a Cox proportional hazards model, our study showed that the overall all-cause discontinuation rate was significantly influenced by the type of medication and not by other variables, such as education level, employment status, and comorbidity, which were significantly different in a simple comparison 
analysis. Although education level was not related to overall treatment or all-cause discontinuation in the current study, there has been evidence of an association between 16 or more years of education nd a lower risk of discontinuation provided by care provided by mental health professionals other than psychiatrists. ${ }^{34,35}$ To this point, there has been little evidence that discontinuation rates are associated with employment status; however, there has been evidence that highincome patients are less likely than patients with low-average incomes to discontinue treatment especially in the later period of treatment process. ${ }^{36}$ Therefore, in evaluating discontinuation risk associated with employment status, consideration should be given to factors beyond simply having an occupation or not; however, the current study assessed only employment status.

In this study, the SSRI group had a higher proportion of comorbidity than the moclobemide group and thus, we put comobidity into the Cox proportional hazard model as a possible factor which could independently affect the all-cause discontinuation rate. However, no association of comobidity with the all-cause discontinuation rate was found in current study. In a further analysis, mood and anxiety disorder appeared to exert little influence on the propensity to all-cause discontinue. Generally, there could be a tendency that patients with comorbid psychiatric disorder were more likely than patients with only one disorder to leave a treatment process in the general sector in the early phase of treatment. ${ }^{37}$ We found that only depression may be possibly associated with the all-cause discontinuation rate in the current study.

In interpreting these findings, we note several limitations. First, the present study involved a relative small patient sample with no strict control of the patient population. In particular, there are two major points regarding the lack of control over patient population. One is another drug's potential effects and the other is the severity of social anxiety symptoms. Evidence has supported that benzodiazepines or beta-blockers are considered effective treatment options in the management of SAD; ${ }^{38}$ however, we did not analyze the confounding effect of these medications in this study. Also, cognitive behavioral therapy or other psychosocial interventions have been reported to influence the treatment response; ${ }^{39}$ however, we did not consider such effects in our retrospective design. Furthermore, as we performed no assessment of the severity of social anxiety symptoms at baseline, a particular group could include more patients with severe or mild symptoms. A clinician's attitude toward treatment could be varied with symptom severity, and this could have possibly influenced treatment persistence. Secondly, the present study did not include clinical parameters for adverse drug events or treatment responses. Generally, researchers have estimated medi- cation adherence or all-cause discontinuation rates by using various methods, such as the length of therapy method (LOT) metric, which estimates time to all-cause discontinuation from data sources like patient self-reports, computerized pharmacy records, or pill counts ${ }^{21,40,41}$ In particular, our study is limited by the fact that we indirectly inferred the reason for all-cause discontinuation via some points of observation. Similarly, the efficacy of both medications could not be confirmed directly from the data. Third, as a naturalistic study using a secondary data analysis, selection bias may have influenced the results. Although comorbidity did not significantly influence the all-cause discontinuation rate in the current study, we cannot rule out the possibility that the clinician in this study may have paid more attention to these patients, because there was a lot of evidence with negative findings regarding the characteristics of comorbidity in SAD. Also, the current study's clinician may have chosen SSRIs to manage a patient's comorbid disorder, as SSRIs have a broader clinical indication with more evidence of efficacy against anxiety and depression. Fourth, many potentially relevant patient characteristics, socio-economic factors, and treatment-related factors were not examined in this study. ${ }^{42}$ Lastly, we could not specify mean doses of medications due to several reasons. Doses of all medications in the current study were determined by clinician judgment in a natural clinical setting. Therefore, the doses were changed for many reasons, such as a patient symptom change or adverse effects during the long treatment period.

Thus, future studies with more subjects and designed with prospective method are needed to confirm the relationships among treatment duration, types of medication, and other clinical variables in the pharmacotherapy of SAD.

In conclusion, despite several limitations, the current study has clinical significance in that it demonstrated a difference in treatment adherence between the SSRIs and moclobemide in the pharmacotherapy of SAD in a natural clinical setting. The present results support the fact that SSRIs, which have better treatment adherence than moclobemide, may contribute to predictions of better treatment response in the pharmacotherapy of SAD in a natural clinical setting.

\section{Acknowledgments}

This study was supported by the Jeong-Gon Kim psychiatry research fund at Kangbuk Samsung Hospital.

\section{REFERENCES}

1. Stein DJ, Stein MB, Pitts CD, Kumar R, Hunter B. Predictors of response to pharmacotherapy in social anxiety disorder: an analysis of 3 placebo-controlled paroxetine trials. J Clin Psychiatry 2002;63:152-155.

2. Wittchen HU, Beloch E. The impact of social phobia on quality of life. Int Clin Psychopharmacol 1996;11(Suppl 3):15-23.

3. Kessler RC, Stein MB, Berglund P. Social phobia subtypes in the National Comorbidity Survey. Am J Psychiatry 1998;155:613-619. 
4. Brunello N, den Boer JA, Judd LL, Kasper S, Kelsey JE, Lader M, et al. Social phobia: diagnosis and epidemiology, neurobiology and pharmacology, comorbidity and treatment. J Affect Disord 2000;60:61-74.

5. Schneier FR, Johnson J, Hornig CD, Liebowitz MR, Weissman MM. Social phobia. Comorbidity and morbidity in an epidemiologic sample. Arch Gen Psychiatry 1992;49:282-288.

6. Liebowitz MR, Schneier F, Campeas R, Hollander E, Hatterer J, Fyer A, et al. Phenelzine vs atenolol in social phobia. A placebo-controlled comparison. Arch Gen Psychiatry 1992;49:290-300.

7. Schneier FR. Treatment of social phobia with antidepressants. J Clin Psychiatry 2001;62(Suppl 1):43-48.

8. Versiani M, Nardi AE, Mundim FD, Alves AB, Liebowitz MR, Amrein R. Pharmacotherapy of social phobia. A controlled study with moclobemide and phenelzine. Br J Psychiatry 1992;161:353-360.

9. Blanco C, Raza MS, Schneier FR, Liebowitz MR. The evidence-based pharmacological treatment of social anxiety disorder. Int J Neuropsychopharmacol 2003;6:427-442.

10. Versiani M, Nardi AE, Mundim FD, Pinto S, Saboya E, Kovacs R. The long-term treatment of social phobia with moclobemide. Int Clin Psychopharmacol 1996;11(Suppl 3):83-88.

11. Noyes R Jr, Moroz G, Davidson JR, Liebowitz MR, Davidson A, Siegel J, et al. Moclobemide in social phobia: a controlled dose-response trial. J Clin Psychopharmacol 1997;17:247-254.

12. Schneier FR, Goetz D, Campeas R, Fallon B, Marshall R, Liebowitz MR. Placebo-controlled trial of moclobemide in social phobia. Br J Psychiatry 1998;172:70-77.

13. Stein MB, Chartier MJ, Hazen AL, Kroft CD, Chale RA, Cote D, et al. Paroxetine in the treatment of generalized social phobia: open-label treatment and double-blind placebo-controlled discontinuation. J Clin Psychopharmacol 1996;16:218-222.

14. Van Ameringen M, Mancini C, Streiner DL. Fluoxetine efficacy in social phobia. J Clin Psychiatry 1993;54:27-32.

15. Bouwer C, Stein DJ. Use of the selective serotonin reuptake inhibitor citalopram in the treatment of generalized social phobia. J Affect Disord 1998;49:79-82.

16. Atmaca M, Kuloglu M, Tezcan E, Unal A. Efficacy of citalopram and moclobemide in patients with social phobia: some preliminary findings. Hum Psychopharmacol 2002;17:401-405.

17. Ackerman DL, Greenland S, Bystritsky A, Morgenstern H, Katz RJ. Predictors of treatment response in obsessive-compulsive disorder: multivariate analyses from a multicenter trial of clomipramine. J Clin Psychopharmacol 1994;14:247-254.

18. Davidson JR, Kudler HS, Saunders WB, Erickson L, Smith RD, Stein $\mathrm{RM}$, et al. Predicting response to amitriptyline in posttraumatic stress disorder. Am J Psychiatry 1993;150:1024-1029.

19. Lader M, Stender K, Burger V, Nil R. Efficacy and tolerability of escitalopram in 12- and 24-week treatment of social anxiety disorder: randomised, double-blind, placebo-controlled, fixed-dose study. Depress Anxiety 2004;19:241-248.

20. Versiani M, Amrein R, Montgomery SA. Social phobia: long-term treatment outcome and prediction of response--a moclobemide study. Int Clin Psychopharmacol 1997;12:239-254.

21. Stein MB, Cantrell CR, Sokol MC, Eaddy MT, Shah MB. Antidepressant adherence and medical resource use among managed care patients with anxiety disorders. Psychiatr Serv 2006;57:673-680.

22. Yamada M, Yasuhara H. Clinical pharmacology of MAO inhibitors: safety and future. Neurotoxicology 2004;25:215-221.

23. Volz HP, Gleiter $\mathrm{CH}$. Monoamine oxidase inhibitors. A perspective on their use in the elderly. Drugs Aging 1998;13:341-355.
24. American Psychiatric Association. Diagnostic and Statistical Manual of Mental Disorders, Fourth Edition. Washington, DC: American Psychiatric Press; 1994.

25. Sheehan DV, Lecrubier Y, Sheehan KH, Amorim P, Janavs J, Weiller E, et al. The Mini-International Neuropsychiatric Interview (M.I.N.I.): the development and validation of a structured diagnostic psychiatric interview for DSM-IV and ICD-10. J Clin Psychiatry 1998;59(Suppl 20):22-33.

26. Stroup TS, McEvoy JP, Swartz MS, Byerly MJ, Glick ID, Canive JM, et al. The National Institute of Mental Health Clinical Antipsychotic Trials of Intervention Effectiveness (CATIE) project: schizophrenia trial design and protocol development. Schizophr Bull 2003;29:15-31.

27. Weiden PJ. Discontinuing and switching antipsychotic medications: understanding the CATIE schizophrenia trial. J Clin Psychiatry 2007; 68(Suppl 1):12-19.

28. Cox D, Oakes D. Analysis of Survival Data. London: Chapman and Hall; 1984.

29. Cox D. Regression models and life tables. J R Stat Soc B 1972;34:187220.

30. Edlund MJ, Wang PS, Berglund PA, Katz SJ, Lin E, Kessler RC. Dropping out of mental health treatment: patterns and predictors among epidemiological survey respondents in the United States and Ontario. Am J Psychiatry 2002;159:845-851.

31. Sonawalla SB, Farabaugh AH, Leslie VM, Pava JA, Matthews JD, Fava M. Early drop-outs, late drop-outs and completers: differences in the continuation phase of a clinical trial. Prog Neuropsychopharmacol Biol Psychiatry 2002;26:1415-1419.

32. Linden M, Osterheider M, Nickelsen T, Schaaf B. Three types of early termination of antidepressant drug treatment. Int Clin Psychopharmacol 1993;8:345-346.

33. Velligan DI, Wang M, Diamond P, Glahn DC, Castillo D, Bendle S, et al. Relationships among subjective and objective measures of adherence to oral antipsychotic medications. Psychiatr Serv 2007;58:1187-1192.

34. Wong JL. Lay theories of psychotherapy and perceptions of therapists: a replication and extension of Furnham and Wardley. J Clin Psychol 1994;50:624-632.

35. Howard KI, Cornille TA, Lyons JS, Vessey JT, Lueger RJ, Saunders SM. Patterns of mental health service utilization. Arch Gen Psychiatry 1996;53:696-703.

36. Weinick RM, Byron SC, Bierman AS. Who can't pay for health care? J Gen Intern Med 2005;20:504-509.

37. Olfson M, Mojtabai R, Sampson NA, Hwang I, Druss B, Wang PS, et al. Dropout from outpatient mental health care in the United States. Psychiatr Serv 2009;60:898-907.

38. Ravindran LN, Stein MB. The pharmacologic treatment of anxiety disorders: a review of progress. J Clin Psychiatry 2010;71:839-854.

39. Stangier U, Schramm E, Heidenreich T, Berger M, Clark DM. Cognitive therapy vs interpersonal psychotherapy in social anxiety disorder: a randomized controlled trial. Arch Gen Psychiatry 2011;68:692-700.

40. Mullins CD, Shaya FT, Meng F, Wang J, Harrison D. Persistence, switching, and discontinuation rates among patients receiving sertraline, paroxetine, and citalopram. Pharmacotherapy 2005;25:660-667.

41. Rickles NM, Svarstad BL. Relationships between multiple self-reported nonadherence measures and pharmacy records. Res Social Adm Pharm 2007;3:363-377.

42. Andersen RM. Revisiting the behavioral model and access to medical care: does it matter? J Health Soc Behav 1995;36:1-10. 